\title{
Exposure as Collected Link Identifier
}

National Cancer Institute

\section{Source}

National Cancer Institute. Exposure as Collected Link Identifier. NCI Thesaurus. Code

C117471.

A sequence of characters used as a linkage between related collected exposure records. 